\title{
Japanese university plan under fire again
}

[TокҮO] Shigehiko Hasumi, the outspoken president of Tokyo University, has strongly criticized a government plan to turn Japan's 'national' universities into semiautonomous agencies with greater administrative independence.

Hasumi, who is also chairman of the Association of National Universities, said at a press conference last week that the government's proposal would be "unsuitable for the university's management, education and research". He added that a plan to introduce evaluation by the Management and Coordination Agency - which oversees government administration - "would further restrict" the universities' freedom.

Hasumi's statements came after a committee of researchers and academics set up by the Ministry of Education, Science, Sports and Culture (Monbusho) decided it was important to increase competition between universities, even at the risk of threatening research and teaching at some of them.

The 99 national universities have been targeted by government reforms aimed at improving administrative efficiency by restructuring government ministries and agencies (see Nature 389, 897; 1997).

Changes have already been proposed for institutes attached to science-related ministries and for the 14 basic research institutes under Monbusho, including the Institute of Space and Astronautical Sciences (ISAS) and the High Energy Accelerator Research Organization (see Nature 398, 272; 1999).

The government had postponed its plan to restructure national universities because of fierce opposition from the academic community and Monbusho (see Nature 395, 730; 1998). But such moves have gathered momentum recently as the result of strong pressure within the government to reduce the number of civil servants by giving agency status to government-run organizations.

In a bid to reduce tension over the move, Monbusho recently set up an ad hoc committee to discuss how the universities might be reformed without affecting the standard of research and education.

The committee - whose members include Minoru Oda, former director of ISAS, Hiroo Imura, former dean of Kyoto
University, and Leo Esaki, former dean of Tsukuba University - held its first meeting last week. It concluded that the current government proposals, which emphasize performance targets related to costs, could jeopardize research and teaching at universities.

But they agreed that some competition must be introduced, perhaps by targeting funding at research groups and institutions with good track records, as opposed to Monbusho's current system, which disperses funds to universities without adequate consideration of their performance.

The committee hopes to agree on a general direction by the autumn and reach a final decision by next summer. But sources close to Monbusho say the ministry sees the creation of agencies as 'inevitable', and that the final decision is likely to be imposed on universities by the government whether they like it or not.

"The administrative reform plan is being forced upon us by the bureaucrats," said Hasumi. "But a serious conflict [between the government and universities] would be inevitable at some point.” AsakoSaegusa

\section{Australia plans research reforms but without extra funding}

[SYDNEY] David Kemp, Australia's minister of education, training and youth affairs, has proposed some major changes in the way research is organized, including giving incentives to some universities to identify "specialized niches" for themselves in research and teaching.

His strategy is based on the universities obtaining extra revenue by commercializing their research more effectively and expanding their research contracts with the private sector.

The government claims its scheme would strengthen research links with industry, which it considers to be a top priority. But Peter Cullen, president of the Federation of Australian Scientific and Technological Societies, describes forcing universities to seek more funding from business as an "unlikely" strategy. "Governments have tried to persuade business to lift their R\&D without any success. What new levers they think the universities have is a puzzle."

Under the proposals, the Australian Research Council (ARC) - earlier rumoured to be facing a major reduction in its powers - would see its influence grow. It would be given enhanced status, with its own act of parliament and a stronger role in giving 'strategic' advice to government and administering grants worth $\mathrm{A} \$ 436$ million (US\$284 million).

ARC's programmes for funding research would be consolidated and become "more

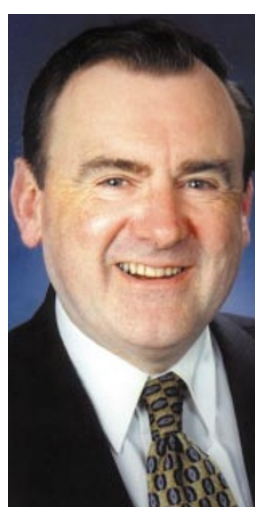

flexible". Vicki Sara, a biomedical scientist who currently chairs ARC, would see her full-time post replaced by a part-time position and a fulltime chief executive.

Sara welcomes the new "independence" of ARC and the "affirmation that excellence must be the hallmark of research Kemp: wants stronger links with industry. training". But most universities are reserving judgement until they have established what the changes will mean for them.

To the concern of those who argue that the main problem facing Australian universities is funding, Kemp stresses that his top priority is to get the strategy right, with resource issues "to be considered down the track".

Brian Anderson, president of the Australian Academy of Science, approves of the "streamlining" of ARC, but warns that it will be beneficial only "if it's accompanied by additional funding". Some of the large, older universities, which dominate ARC grants, fear a considerable loss of support.

The 'group of eight' universities, which win around four-fifths of competitive grants, is opening an office in Canberra to promote and protect their position.

Ministers of the coalition government have ordered an unrelenting squeeze on academia over four budgets. The May 1999 budget, for example, cut 'targeted research' by 5.5 per cent and 'other higher education $R \& D$ ' by 2 per cent.

John Niland, president of the Australian Vice-Chancellors' Committee, calculates that the group of eight, of which his own University of New South Wales is a member, faces an overall loss of A $\$ 17$ million. But some smaller, regional universities believe they will get more funding for research.

Niland says that the proposal hides a centralization of direction and control of research, and thinks universities will have to do more paperwork - generating binding strategic research plans, for example - to justify their block funding for research. He says this could either "restrict the diversity" of research or be "little more than a timeconsuming paper shuffle".

Kemp says his personal priority is the funding of all postgraduate students through scholarships that they can use at the university of their choice or take to another.

Within existing funding, Kemp claims that hundreds of millions of dollars will be saved by limiting the period of masters to two years and doctorates to three-and-a-half years. Universities have four months to comment on his proposals. Peter Pockley 